Vacuum Insulator Development for the Dielectric Wall Accelerator

J. R. Harris, D. Blackfield, G. J. Caporaso, Y.-J. Chen, S. Hawkins, M. Kendig, B. Poole, D. M. Sanders, M. Krogh, J. E. Managan

March 20, 2008

Journal of Applied Physics 
This document was prepared as an account of work sponsored by an agency of the United States government. Neither the United States government nor Lawrence Livermore National Security, LLC, nor any of their employees makes any warranty, expressed or implied, or assumes any legal liability or responsibility for the accuracy, completeness, or usefulness of any information, apparatus, product, or process disclosed, or represents that its use would not infringe privately owned rights. Reference herein to any specific commercial product, process, or service by trade name, trademark, manufacturer, or otherwise does not necessarily constitute or imply its endorsement, recommendation, or favoring by the United States government or Lawrence Livermore National Security, LLC. The views and opinions of authors expressed herein do not necessarily state or reflect those of the United States government or Lawrence Livermore National Security, LLC, and shall not be used for advertising or product endorsement purposes. 


\title{
Vacuum Insulator Development for the Dielectric Wall Accelerator
}

\author{
J.R. Harris ${ }^{\text {a) }}$, D. Blackfield, G.J. Caporaso, Y.-J. Chen, S. Hawkins, M. Kendig, B. Poole, \\ and D.M. Sanders
}

Lawrence Livermore National Laboratory, Livermore CA 94551

\author{
M. Krogh
}

Complete Compact Aero Operation Systems, Inc., Lees Summit, MO 64081

\section{J.E. Managan}

Department of Physics and Astronomy, Vanderbilt University, Nashville TN 37235

Abstract

At Lawrence Livermore National Laboratory, we are developing a new type of accelerator, known as a Dielectric Wall Accelerator, in which compact pulse forming lines directly apply an accelerating field to the beam through an insulating vacuum boundary. The electrical strength of this insulator may define the maximum gradient achievable in these machines. To increase the system gradient, we are using "High Gradient Insulators" composed of alternating layers of dielectric and metal for the vacuum insulator. In this paper, we present our recent results from experiment and simulation, including the first test of a High Gradient Insulator in a functioning Dielectric Wall Accelerator cell.

a) Electronic mail: harris89@1lnl.gov 


\section{Introduction}

At Lawrence Livermore National Laboratory, we are developing a new type of linear induction accelerator known as the Dielectric Wall Accelerator (DWA) $)^{1,2}$. DWAs use stacked pulse-forming lines to directly apply an accelerating field to the beam through an insulating vacuum boundary, or "dielectric wall" (Fig. 1). Variants of this technology will be suitable for a number of applications, including radiography ${ }^{3}$ and radiation therapy ${ }^{4}$. The desire for compact systems and high accelerating gradients in these machines has driven improvements in several areas, especially transmission lines ${ }^{5}$, dielectric materials ${ }^{6}$, and fast photoconductive switching ${ }^{7}$. One of the ultimate technical limitations on the DWA concept is likely to be the electrical strength of the dielectric wall itself. The limiting factor in the design of high voltage vacuum insulators is generally vacuum surface flashover, rather than the bulk strength of the insulating material $^{8}$. The most widely accepted theory of surface flashover holds that an avalanche of secondary electrons occurs along the insulator surface, desorbing gas through which the breakdown occurs ${ }^{8-11}$. The gradients envisioned for DWAs, and especially the 100 $\mathrm{MV} / \mathrm{m}$ gradient envisioned for proton radiotherapy, are well beyond the capabilities of conventional, straight-walled vacuum insulator materials. A number of techniques, such as angled insulators or applied magnetic fields, can increase the voltage at which flashover occurs by making it more difficult for secondary electrons to return to the insulator surface ${ }^{8}$. However, insulators in the DWA will be subjected to voltage reversals, preventing optimized use of angled insulators which have a preferred polarity, and the strong magnetic fields needed for magnetic flashover inhibition are not desirable as they would complicate beam transport. In support of DWA development, we are 
currently studying multilayer High-Gradient Insulators (HGIs) ${ }^{12}$. HGIs are vacuum insulating structures composed of alternating layers of metal and dielectric (Fig. 2). This concept was originally identified by several researchers based on the observation that the electric field strength needed to initiate flashover of conventional vacuum insulators increased with decreasing length ${ }^{8}$, and pioneering experiments were performed by Smith $^{13}$, Gray ${ }^{14}$, and Pillai and Hackam ${ }^{15}$. When properly designed, these structures have shown the capability to withstand higher voltages than conventional (un-angled) insulators by a factor from 1.5 to $4^{14}$, an improvement which is comparable to that obtained by use of angled insulators ${ }^{8}$, and gradients of $100 \mathrm{MV} / \mathrm{m}$ have been demonstrated for small structures subjected to nanosecond pulses ${ }^{16}$. Despite these promising results, no comprehensive explanation of the operating mechanism of HGIs has emerged, and experiments carried out by different researchers have yielded contradictory results. In this paper we report the results of our recent experiments with HGIs, including testing in an integrated DWA structure, and compare our results to those in the literature. We also show how displacement current may affect the flashover process in short-pulse, high-gradient DWAs.

\section{Small Sample Testing}

To investigate the conditionability of HGIs, and to determine what effect the choice of insulator and metal layer thicknesses has on their strength, we tested a number of HGIs consisting of thin Rexolite and stainless steel layers, hot pressed and machined to the final $2.54 \mathrm{~cm}$ diameter (Fig. 3). These samples are listed in Tables I - III. In this section, we describe our testing procedures and results, and compare these to results reported in the literature. 


\section{A. Testing Procedures and Conditioning}

Testing is conducted using a dedicated high voltage test stand ${ }^{12}$. In this test stand, the samples are held between stainless steel electrodes in a vacuum chamber pumped to $2 \mathrm{x}$ $10^{-7}$ Torr. A negative voltage pulse from a 16-stage Marx generator is applied to the upper electrode. This pulse has a rise time of 10 ns, a FWHM pulse length of $100 \mathrm{ns,}$, and a peak voltage adjustable from $60 \mathrm{kV}$ to $290 \mathrm{kV}$ (Fig 4). The output voltage of the Marx is approximately 12 times the charging voltage over most of its operating range. In previous tests without an insulator between the electrodes, no vacuum arc occurred until the gradient reached $42 \mathrm{MV} / \mathrm{m}$, which is well above the flashover strength of the insulators tested. Testing is normally accomplished by applying one pulse per minute to the sample, and increasing the Marx charging voltage by $500 \mathrm{~V}$ after every $n$th shot until a flashover occurs. The Marx charging voltage is then reduced by $500 \mathrm{~V}$ and the process repeats. This continues until $m$ flashovers have occurred at a single charging voltage level. Typically, $n=5$ and $m=3$. The highest voltage or gradient held without flashover during testing is taken to be the insulator strength.

The choice of test procedure, and in particular $n$ and $m$, will affect the test results. Increasing the number of shots $(n)$ taken at each voltage level before advancing to the next voltage level serves to increase the high-voltage conditioning of the sample during the test. To investigate this, insulators R168, R169, and R170 were tested using the standard procedure, except that they were subjected to one, five, and ten shots, respectively, at each voltage level before proceeding to the next voltage level. The resulting conditioning of R169 and R170 increased the voltage at which the first flashover was observed, but it did not have a discernible effect on the peak voltage 
sustained. Results for these insulators are summarized in Fig. 5 along with those for $\mathrm{R} 173^{12}$, which was frequently removed from vacuum during testing and therefore did not receive the same conditioning benefits. Fig. 6 shows the percentage of successful shots (solid) and the total number of shots (dot) at each charging voltage for these four HGIs. The highest voltage held without flashover for each of the HGIs is close to the voltage at which $50 \%$ of the shots did not result in flashovers, as shown in these curves. This suggests that the "highest voltage held without flashover" is a meaningful way to quote the HGI strength. The smaller number of shots used for R168 increased the granularity of the plot for that HGI. Sample R169 showed inferior performance compared to R168 and R170. This is believed to be due to a mechanical deformation of the structure observed in microphotographs taken before testing (Fig. 7). Images taken after testing show that the main regions of damage corresponded to the location of minimum spacing between adjacent metal layers.

Following testing, the samples remained under vacuum for over 24 hours, and were tested again using $n=1$. For each sample, the first flashover occurred at a voltage which was higher than the first flashover in the previous test, but lower than the peak voltage held during the previous test (Fig. 5). This indicates that the flashovers occurring in the initial testing had a net conditioning effect, and that some of that conditioning was retained permanently, presumably due to physical changes in the insulator surface or removal of surface contaminants.

It was also important to establish whether the reported value of insulator strength would increase significantly by requiring a higher number of flashovers to occur at a given voltage level before the test was concluded $(m)$. To investigate this, three HGIs with 
different layer thicknesses were tested until a total of five flashovers were observed at any voltage level. The highest peak voltage sustained by the insulator before the first, second, third, fourth, and fifth flashovers at any voltage level are plotted in Fig. 8. This figure shows that continuing the tests beyond $m=3$ did not significantly improve the reported strength in any of the three samples.

Finally, tests were also carried out using samples R207-R212 to determine if conditioning could be achieved by applying a series of extra pulses at the lowest voltage achievable in the test stand before beginning the standard test procedure, and to investigate the effect of reducing the Marx capacitance and stored energy. These tests yielded inconsistent results, and no dependence on conditioning procedure was apparent. These results are shown in Table I.

Other investigators have reported mixed results with attempts to condition HGIs. Conditioning was observed by Elizondo in structures formed from Lexan interleaved with thin stainless steel sheets ${ }^{17}$, and by Leopold in structures formed from alumina and thick Kovar rings ${ }^{18}$. Conditioning was not observed by Sampayan in structures formed from silica with sputtered gold electrodes ${ }^{19}$. All of these tests were conducted with pulsed voltages, with pulse lengths varying from about $20 \mathrm{~ns}$ to about $2 \mu \mathrm{s}$. DC tests on HGIs previously conducted at Livermore also showed gradual conditioning during testing, but these samples did not retain their conditioning for any significant period ${ }^{20}$. The best alumina structure tested by Leopold did not exceed the breakdown strength of conventional structures until after 2500 conditioning pulses ${ }^{18}$, which may be partly due to a slower conditioning process than was seen by us. In fact, the conditioning procedures used by us may be too aggressive. This is suggested by the improved performance 
resulting from larger numbers of shots per voltage level $(n)$, and by the surface damage observed in our samples, particularly the ablation and redeposition of metal which occurred in extreme cases ${ }^{12}$. While such large-scale movement of metal is certainly unhelpful, small-scale movement of metal may play a role in the conditioning effects we see by removing metal structures that are sources of field emission. This process requires a certain amount of energy, which would explain why our attempts to condition samples with low voltage pulses were unsuccessful. The inability to condition observed by Sampayan may have been due to a lower damage threshold for the sputtered gold electrodes, which were only $20,000 \AA$ thick $^{21}$.

\section{B. Dependence on Sample Geometry}

A key concern of these tests was to search for ways to increase the strength of HGIs by changing the thickness of the metal $(M)$ and insulator $(I)$ layers, and so a variety of sample geometries were tested. Table II shows results of tests using HGIs with lengths of approximately $11 \mathrm{~mm}$, and several values of insulator layer thickness; the metal layer thickness for all of these samples was $0.013 \mathrm{~mm}$. In addition, we tested four samples with metal layers that were slightly thicker than the insulator layers, as shown in Table III. This geometry was suggested by the work of Leopold, who attempted to explain the improved performance of HGIs in terms of electron deflection away from the

HGI-vacuum interface ${ }^{18}$. This effect relies on the curvature of equipotential lines near the HGI surface, and requires relatively thick metal layers $(I / M<3)$. In addition, the effect should be sensitive to the choice of metal or dielectric for the initial layer, with an initial metal layer being preferred. Results from Leopold's experiments agreed very well with his predictions based on this model. Our samples listed in Table III were initially 
fabricated with dielectric end layers, but two were modified by removal of those end layers. Fig. 9 shows the results from Tables 2 and 3 plotted as a function of $I / M$. In our tests, HGI strength generally increased with increasing $I / M$, and the thick-metal HGIs performed more poorly than the thin-metal HGIs. In addition, there was no clear difference between thick-metal HGIs having metal end layers and those having dielectric end layers. The structure period $(I+M)$ for the thick-metal HGIs used in our experiments $(0.57 \mathrm{~mm})$ was significantly less than that used in Leopold's work $(4 \mathrm{~mm})$. As described in Ref. 18, this should result in a weaker deflection of the electron trajectories by our samples. If the deflection was sufficiently weak, these trajectories would be close enough to the HGI that they would be intercepted by the unavoidable irregularities present on its surface. Simulations of $4 \mathrm{~mm}$ and $0.57 \mathrm{~mm}$ period HGI structures using the COMSOL MultiPhysics finite element electrostatic code (Fig. 10) confirmed that the expected typical electron heights above the HGI surface would be larger than the $\sim 10 \mu \mathrm{m}$ surface structure actually present on the $0.57 \mathrm{~mm}$ period HGIs tested by us, and therefore excessive interception of low-altitude electrons resulting from weaker deflection is not likely to explain the differences between our results and those of Leopold.

Our experimental results suggest that continuing to increase the insulator layer thickness may result in further improvements in insulator strength. However, at some point an optimum ratio will be reached, beyond which continuing to make the insulator layers thicker will reduce the structure performance. As $I / M \rightarrow \infty$, the structure will no longer be an HGI, and therefore we expect the strength in this limit to return to the strength of bare Rexolite, previously measured as $16.6 \mathrm{MV} / \mathrm{m}$ in our test stand ${ }^{12}$. 
Several other researchers have investigated the geometric scaling behavior of multilayer vacuum insulators under pulsed voltages. Elizondo ${ }^{17,22}$ and Cravey ${ }^{23}$ reported performance that generally increased with $I / M$. This agrees with our own results, which is not surprising given the very similar nature of the structures tested by Elizondo, Cravey, and us.

Like Leopold, Sampayan found improved performance by using thinner insulator layers $^{19}$. In particular, he found that the breakdown gradient scaled with the inverse root of the dielectric layer thickness, as expected based on previous results for the length scaling of conventional insulators ${ }^{8}$. Sampayan interpreted this as indicating that the dielectric layers in his samples were decoupled and effectively operating as independent insulators.

Note that in the Leopold experiments, the period $I+M$ was held constant and both $I$ and $M$ were varied, while in the other experiments the metal thickness $M$ was generally held constant and the insulator thickness $I$ was varied.

\section{Displacement Current Effects}

As with conventional insulators ${ }^{8}$, HGIs are able to withstand higher gradients as the duration of the applied voltage decreases ${ }^{16,19,23}$. We are currently developing a compact accelerator for proton radiotherapy which will take advantage of this effect ${ }^{4}$. By adjusting the DWA switch timing, the highest gradients can be limited to a small region of the dielectric wall, which moves along the structure as a virtual traveling wave to remain in synch with the accelerating beam. Shortening this region of excitation decreases the effective pulse length seen by any portion of the vacuum insulator. As long as the axial length of the excited region is larger than the beam tube diameter, the electric 
field on axis will be a large fraction of the field applied to the dielectric wall ${ }^{2}$. For a 100 $\mathrm{MV} / \mathrm{m}$ proton radiotherapy accelerator, these considerations suggest a pulse length of about $3 \mathrm{~ns}$, resulting in extremely high $d E / d t$ in the accelerating structure. Under such conditions, the magnetic field generated by the displacement current in the structure is sufficient to alter the trajectories of low energy electrons emitted from the insulator surface by field emission or secondary emission ${ }^{24}$. This may affect the strength of the vacuum insulators by influencing the secondary electron avalanche process. This effect depends in part on the insulator geometry: on the outside of a cylindrical insulator, electrons will be deflected towards the insulator surface during the leading edge of an applied voltage pulse, while on the inside of a hollow cylindrical insulator, electrons will be deflected away from the insulator surface during the leading edge. To further investigate this effect in accelerator-type geometries, simulations were performed using the particle-in-cell code LSP $^{25}$. Fig. 11 shows one such simulation of an electron launched from the inside surface of a hollow dielectric cylinder with an inside diameter of $4 \mathrm{~cm}$. A voltage pulse is applied to the cylinder producing an electric field directed in the $\hat{z}$ direction. This field rises linearly to $2 \mathrm{MV} / \mathrm{m}$ in $0.5 \mathrm{~ns}$, and then falls linearly to 0 $\mathrm{MV} / \mathrm{m}$ over the next $0.5 \mathrm{~ns}$. The electron's initial energy was $2 \mathrm{eV}$, and it was launched normal to the dielectric surface $0.2 \mathrm{~ns}$ into the voltage pulse. On the leading edge of the voltage pulse, the magnetic field deflects the electron away from the dielectric surface, while on the trailing edge it deflects the electron towards the surface. The same case was simulated with LSP modified to ignore magnetic forces when calculating the electron trajectory, and those results are also shown in Fig. 11.

IV. Insulator Testing in a Dielectric Wall Accelerator 
The first integrated test of a DWA using multilayer vacuum insulators driven by pulse-forming lines has recently been completed ${ }^{26}$. This machine consisted of four Blumlein pulse forming lines ${ }^{5}$, each driving a single HGI beam tube (Fig. 12). This cell was configured as a booster for Lawrence Livermore's 5.5 MeV ETA-II induction accelerator $^{27}$. The voltage applied across the insulator stack was directly measured, and a scattering wire energy analyzer ${ }^{28}$ was used to verify that energy was added to the beam. The insulators used in this experiment were each $3.5 \mathrm{~cm}$ thick, with 1 mil stainless steel layers, polyimide dielectric layers, and an approximate insulator-to-metal ratio of 12. These insulators were produced from the same material used in previous tests on ETA-II, in which a modified induction cell was used to apply over $18 \mathrm{MV} / \mathrm{m}$ to an HGI in the presence of beam $^{29,30}$

In the recent tests, the pulse forming lines produced a bipolar voltage waveform consisting of three $20 \mathrm{~ns}$ pulses of alternating polarity, with a peak voltage of $600 \mathrm{kV}$ being applied across the vacuum insulator stack. Energy analyzer measurements confirmed that the DWA cell had modulated the energy of the $1 \mathrm{kA}, 70$ ns ETA-II electron beam. The peak gradient across the insulator stack was $3-4 \mathrm{MV} / \mathrm{m}$, which is approximately ten times higher than the average gradient of ETA-II itself. Because of the metal fixtures used to assemble the HGIs into a stack, the peak gradient across the insulators themselves was higher, reaching approximately 5 - $6 \mathrm{MV} / \mathrm{m}$. During testing, several hundred shots were conducted in the presence of beam. The vacuum insulators suffered no failures, even though it is believed that they were directly struck by the beam on several occasions. V. Conclusion. 
In this paper, we discussed results from our recent testing of HGIs. We found that proper high-voltage conditioning of the insulators could delay the onset of flashovers during testing, and that the observed conditioning consisted of both a permanent and a temporary part. The voltage-holding capability of HGI configurations tested increased as $I / M$ was made larger, although we expect that this result will not hold for very large values of $I / M$. We compared our results to those previously reported in the literature, and in general found good agreement with tests on HGIs of similar construction. The performance of HGIs with significantly different geometries or materials differed greatly from our tests. These divergent results suggest that there are a number of unidentified, underlying variables influencing these structures' performance. We also demonstrated the role played by displacement current in altering the trajectories of low energy electrons characteristic of secondary electron emission avalanche. Finally, we reported the successful performance of an HGI tested in an actual DWA and operated under modest gradient, high current conditions.

\section{ACKNOWLEDGEMENTS}

R. Anaya, E. Gower, C. Holmes, and J. Stanley provided invaluable assistance with experimental work. DWA cell testing on ETA-II was conducted by G. Guethlein, M. Rhodes, J. Watson, and J. Wier. This work was performed under the auspices of the U.S. Department of Energy by Lawrence Livermore National Laboratory under Contract DEAC52-07NA27344. 


\section{REFERENCES}

1 This is an extended and revised version of a paper presented at the 2007 Particle Accelerator Conference, Albuquerque, NM, June 25-29, 2007.

2 G.J. Caporaso, D. Blackfield, Y.-J. Chen, J. R. Harris, S. Hawkins, C. Holmes, S.

D. Nelson, A.C. Paul, B. R. Poole, M. Rhodes, S. Sampayan, D. Sanders, J.

Sullivan, L. Wang, J. Watson, W. Nunnally, K. Selenes, M. Krogh, in Proceedings of the 2007 Particle Accelerator Conference, Albuquerque, NM, June 25-29, 2007.

J.F. McCarrick, G.J. Caporaso, and Y.-J. Chen, in Proceedings of the 2005 Particle Accelerator Conference, Knoxville, TN.

4

G.J. Caporaso, S. Sampayan, Y.-J. Chen, J. Harris, S. Hawkins, C. Holmes, M.

Krogh, S. Nelson, W. Nunnally, A. Paul, B. Poole, M. Rhodes, D. Sanders, K.

Selenes, J. Sullivan, L. Wang, J. Watson, Nuclear Instruments and Methods in

Physics Research B 261 777-781 (2007).

5

M.A. Rhodes, J. Watson, D. Sanders, S. Sampayan, and G. Caporaso, in

Proceedings of the 2007 IEEE Pulsed Power and Plasma Science Conference,

Albuquerque, NM, June 17 - 22, 2007.

6

D.M. Sanders, E.G. Cook, E.M. Anaya, L. Wang, S.E. Sampayan, G.J. Caporaso,

K.M. Slenes, J. Jacquin, and R. De L Fuenta, in Proceedings of the 2007 IEEE

Pulsed Power and Plasma Science Conference, Albuquerque, NM, June 17-22, 2007.

7 J.S. Sullivan and J.R. Stanley, in Proceedings of the 2007 IEEE Pulsed Power and

Plasma Science Conference, Albuquerque, NM, June 17-22, 2007.

$8 \quad$ H. Craig Miller, IEEE Trans. Elect. Insul. 24 765-785 (1989). 
H. Boersch, H. Hamisch, and W. Erlich, Z. Agnew. Physik 15 518-525 (1963).

R.A. Anderson and J.P. Brainard, J. Appl. Phys. 51 1414-1421 (1980).

E.W. Gray, J. Appl. Phys. 58132 (1985).

J.R. Harris, R.M. Anaya, D. Blackfield, Y.-J. Chen, S. Falabella, S. Hawkins, C.

Holmes, A.C. Paul, S. Sampayan, D.M. Sanders, J. Stanley, J.A. Watson, G.J.

Caporaso, M. Krogh, IEEE Transactions on Dielectrics and Electrical Insulation 14 796-802 (2007).

Ian D. Smith, personal communication, 2006.

S.E. Sampayan, P.A. Vitello, M.L. Krogh, and J.M. Elizondo, in Proc. XVIIIth Intern. Symp. Discharges and Elect. Insul. in Vacuum, Volume 2, p. 740-743, Eindhoven, The Netherlands, Aug. 17-21, 1998.

A.S. Pillai and R. Hackam, J. Appl. Phys. 58 146-153 (1985); see Section V. p. 152.

6 W.C. Nunnally, M. Krogh, C. Williams, F. Allen, D. Trimble, S. Sampayan, and G. Caporaso, in Digest of Technical Papers, 2003 Pulsed Power Conference, Volume 1, p. 301-304 (2003).

J.M. Elizondo, in Proceedings of the Ninth International Pulsed Power Conference, p. 257 (1993).

J.G. Leopold, U. Dai, Y. Finkelstein, E. Weissman, and S. Humphries, IEEE Trans. Dielectrics and Elect. Insul. 12, p. 530 (2005).

S.E. Sampayan, P.A. Vitello, M.L. Krogh, and J.M. Elizondo, IEEE Transactions on Dielectrics and Electrical Insulation 7 334-339 (2000).

S. Falabella, personal communication, 2007. 
D.M. Sanders, personal communication, 2007.

J.M. Elizondo, A. Dragt, M. Krogh, D. Brooks, R. Smelser, P. Aragon, H. Happek,

D. Torres, K.D. Ware, and K.R. Prestwich, in Digest of Technical Papers, 12th

IEEE International Pulsed Power Conference, Volume 1, pp. 446-449 (1999).

W.R. Cravey, G.L. Devlin, C.S. Mayberry, and J.N. Downing, in Proceedings of the 1997 Pulsed Power Conference, pp 555-558 (1997).

J.R. Harris, G.J. Caporaso, D. Blackfield, and Y.-J. Chen, Applied Physics Letters 91121504 (2007).

J.E. Managan and J.R. Harris, "Simulation of Electron Trajectories Inside an Annular Dielectric," (2007). Available:

http://www.scied.science.doe.gov/scied/Abstracts2007/LLNL.htm

S. Sampayan, G. Caporaso, Y.-J. Chen, S. Falabella, G. Guethlein, J. Harris, S.

Hawkins, C. Holmes, M. Krogh, S. Nelson, B. Poole, R. Richardson, M. Rhodes, D. Sanders, K. Selenes, J. Sullivan, L. Wang, J. Watson, and J. Wier, IEEE Transactions on Plasma Science, in press (2008).

J.C. Clark, F.E. Coffield, F.J. Deadrick, M.A. Newton, W.E. Nexsen, D. Prono, D.S. Ravenscroft, A.L. Throop, W.C. Turner, and K. Whitham, in Proceedings of the Linear Accelerator Conference, Williamsburg, VA, October 3-7, 1988. UCRL99201. Available: https://e-reports-ext.llnl.gov/pdf/208770.pdf

T.J. Fessenden, "The DARHT Scattering Wire Spectrometer: Operation and Checkout on ETA-II," Lawrence Livermore National Laboratory Report, UCRLTR-213410, July 6, 2005. Available:

http://www.llnl.gov/tid/lof/documents/pdf/317575.pdf 
G.J. Caporaso, in Proceedings of the 25th Intern. Power Modulator Symposium, Hollywood, CA, pp. 679-683 (2002).

30 S. E. Sampayan, G.J. Caporaso, W.C. Nunnally, D.M. Sanders, J.A. Watson, M.L. Krogh, and H.U. Anderson, in Conference Record of the 26th international Power Modulator Symposium, p. 46-49 (2004). 


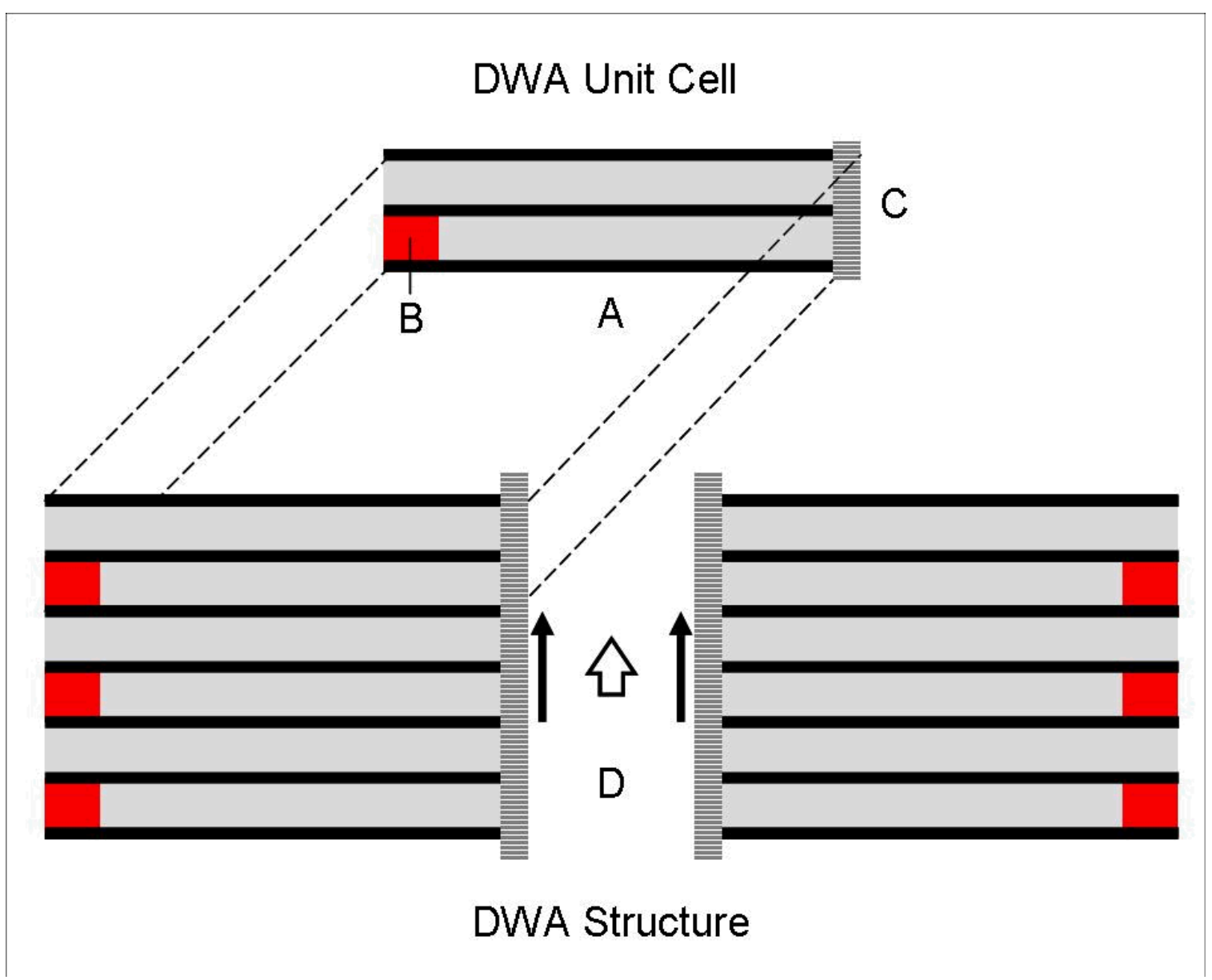

Figure 1. (Color online.) DWA schematic, showing pulse-forming line (A), fast switch (B), vacuum insulator (C), and vacuum region (D) with electric field applied to the dielectric wall to accelerate beam on axis. 


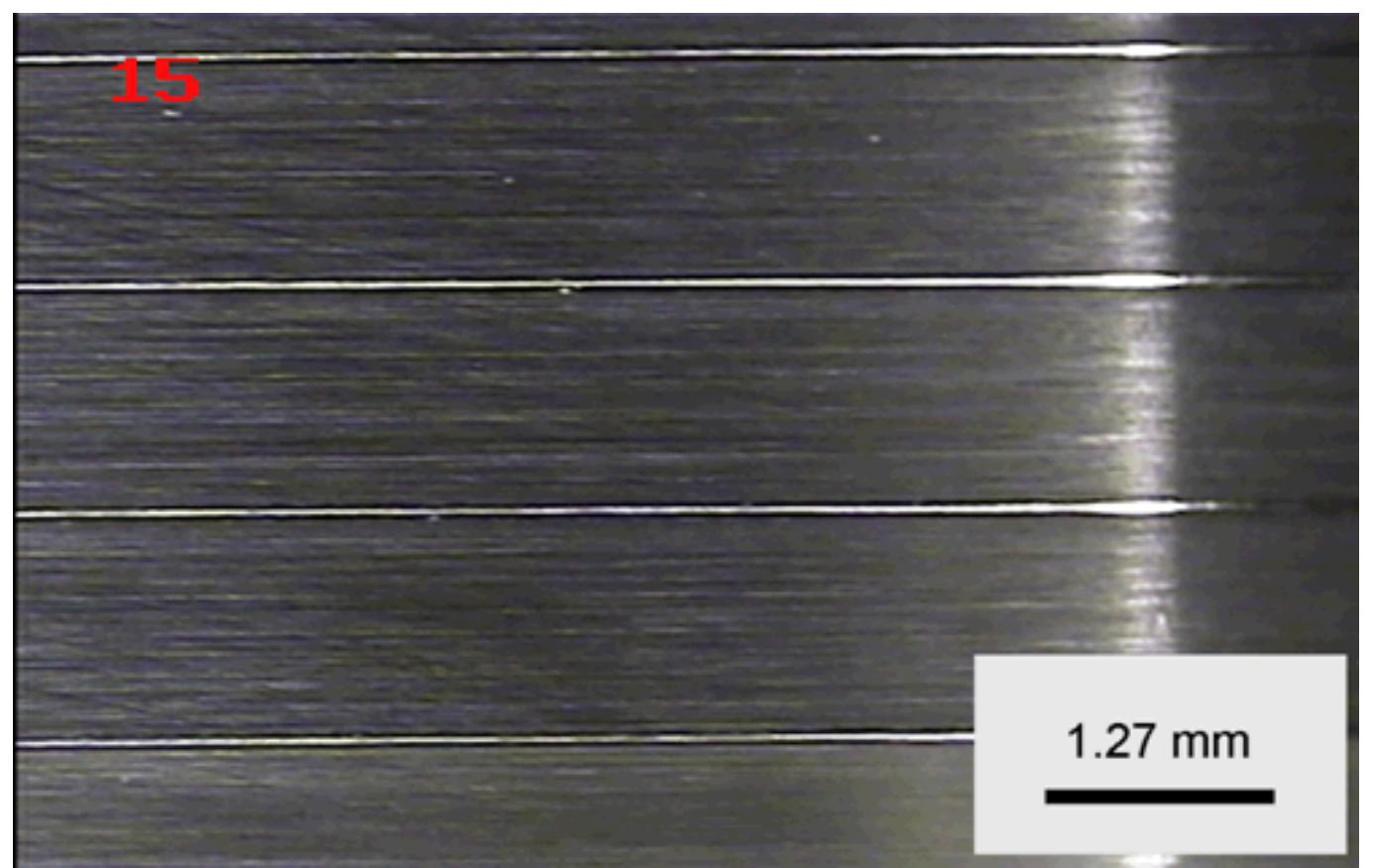

Figure 2. (Color online.) Microphotograph of HGI surface (R213). The thin horizontal lines are stainless steel layers, while the remainder of the structure is Rexolite. 


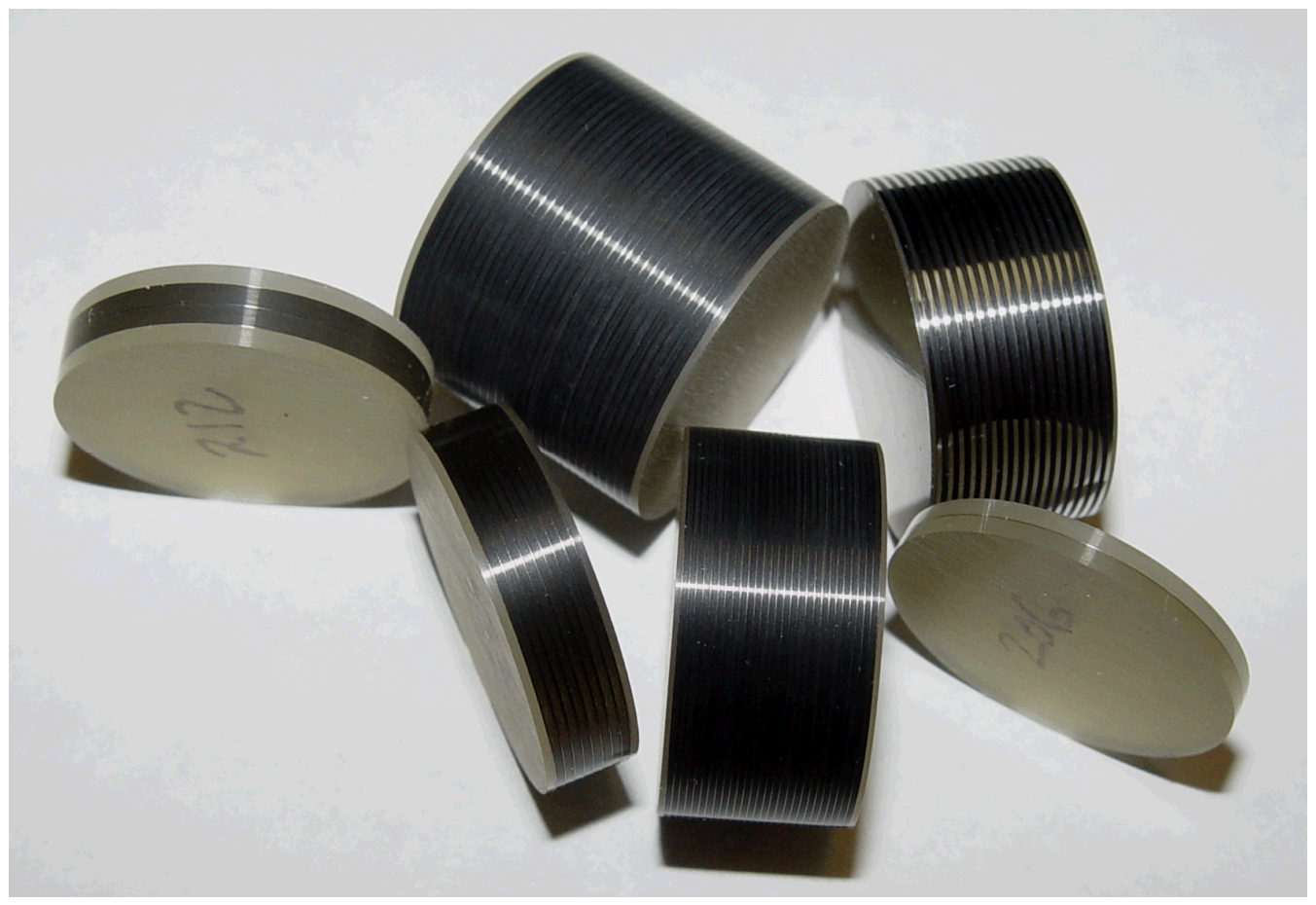

Figure 3. (Color online.) $2.54 \mathrm{~cm}$ diameter HGI samples. 


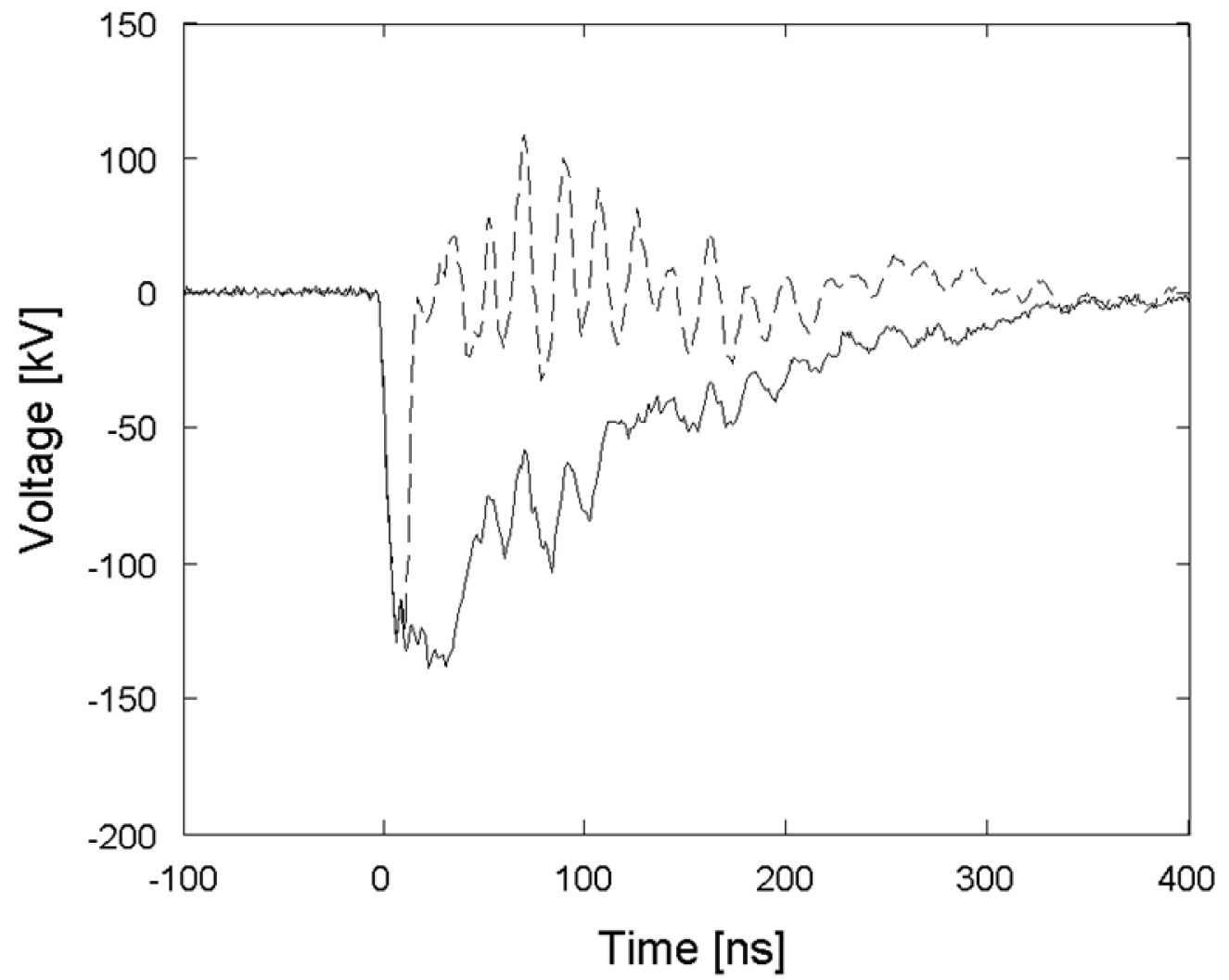

Figure 4. Voltage waveform for 16 stage marx, showing a normal trace (solid) and a typical insulator flashover (dash). 


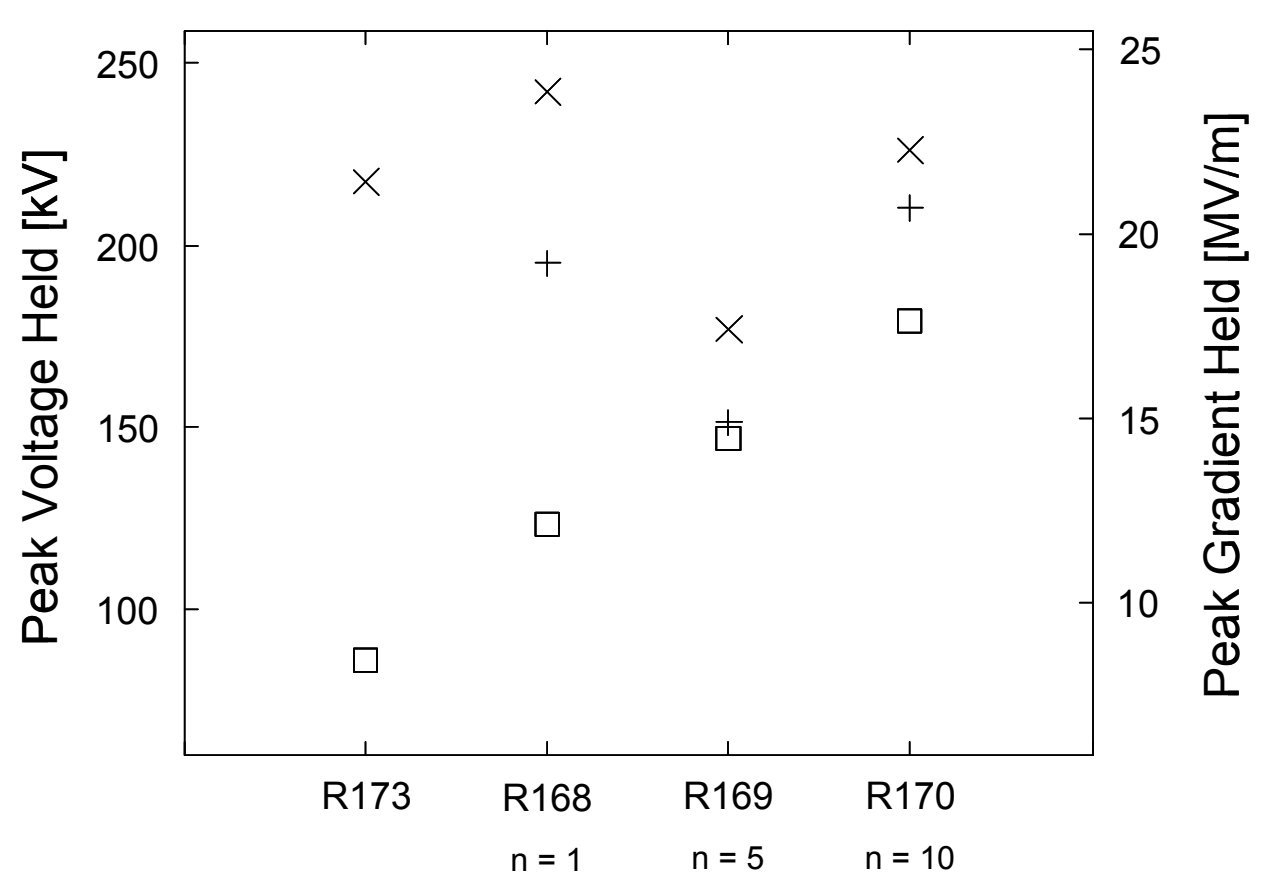

Figure 5. Observed HGI performance as a function of conditioning procedure. The highest voltage achieved before the first flashover $(\square)$ and the highest voltage achieved (X) on the first day, and highest voltage achieved before the first flashover on the second day $(+)$ are shown. 

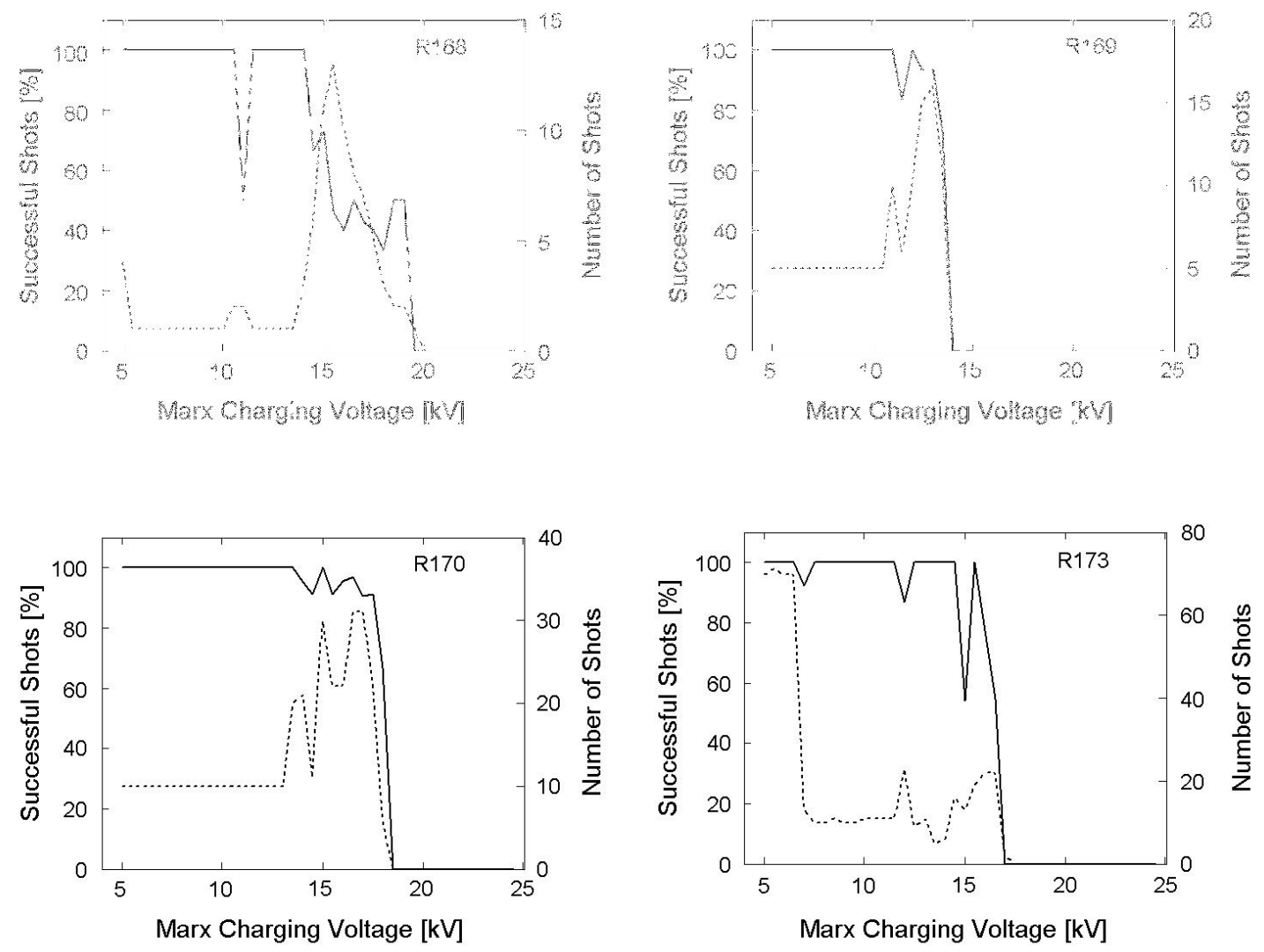

Figure 6. Percentage of successful shots (solid) and total number of shots (dot) as a function of Marx charging voltage for HGIs R168, R169, R170, and R173. 


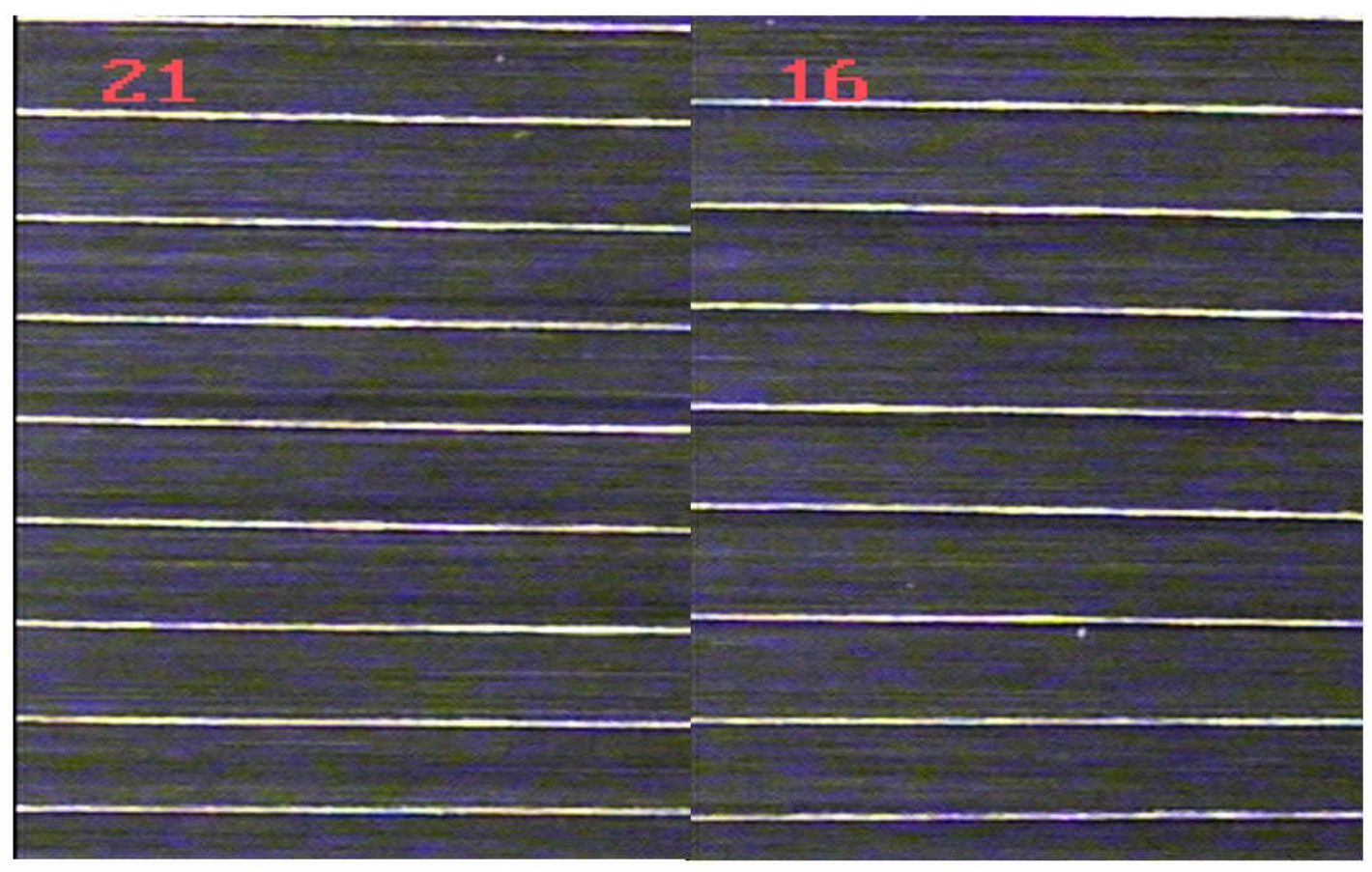

Figure 7. Microphotographs from two locations on R169, showing the difference in layer spacing due to HGI deformation. 


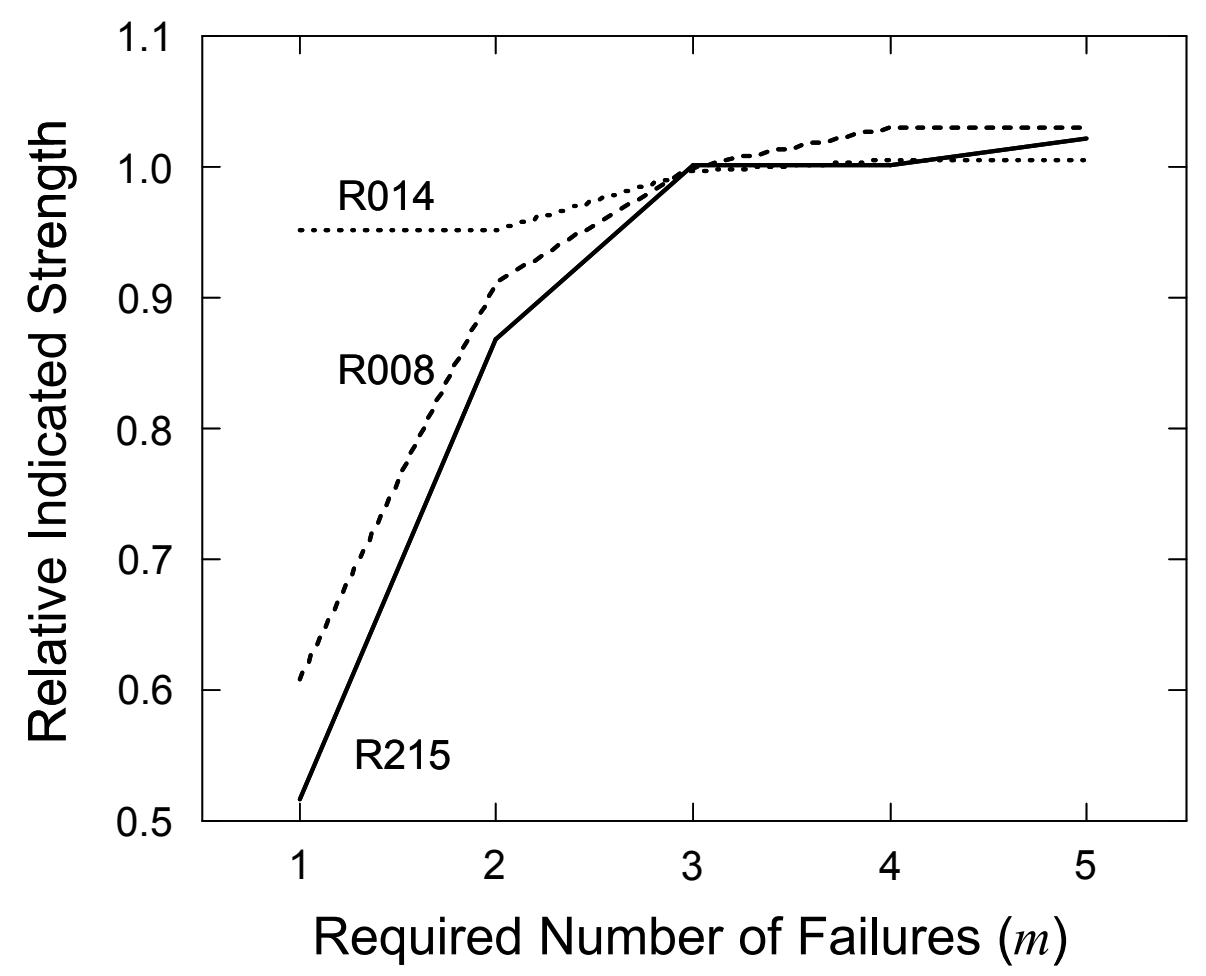

Figure 8. Observed HGI performance as a function of testing procedure. The plotted sample strength is relative to values from Tables 2 and 3. 
Table I: HGI Samples with 5.48 mm length.

\begin{tabular}{|l|c|c|c|l|}
\hline \multicolumn{1}{|c|}{ HGI } & $\begin{array}{c}\text { Rexolite } \\
{[\mathrm{mm}]}\end{array}$ & $\begin{array}{c}\text { Insulator/ } \\
\text { Metal Ratio }\end{array}$ & $\begin{array}{c}\text { Length } \\
{[\mathrm{mm}]}\end{array}$ & $\begin{array}{c}\text { Strength } \\
{[\mathrm{MV} / \mathrm{m}]}\end{array}$ \\
\hline R207 & 1.3 & 100 & 5.48 & 31.7 \\
\hline R208 & 1.3 & 100 & 5.48 & $16.7^{1}$ \\
\hline R209 & 1.3 & 100 & 5.48 & $12.3^{2}$ \\
\hline R210 & 1.3 & 100 & 5.48 & 12.3 \\
\hline R211 & 1.3 & 100 & 5.48 & $28.9^{3}$ \\
\hline R212 & 1.3 & 100 & 5.48 & $21.0^{3}$ \\
\hline
\end{tabular}

${ }^{1} 50$ preliminary conditioning shots at lowest voltage

${ }^{2} 10$ preliminary conditioning shots at lowest voltage

${ }^{3}$ Marx in 11-stage configuration 
Table II: HGI Samples with 11 mm length.

\begin{tabular}{|l|c|c|c|l|}
\hline \multicolumn{1}{|c|}{ HGI } & $\begin{array}{c}\text { Rexolite } \\
{[\mathrm{mm}]}\end{array}$ & $\begin{array}{c}\text { Insulator/ } \\
\text { Metal Ratio }\end{array}$ & $\begin{array}{c}\text { Length } \\
{[\mathrm{mm}]}\end{array}$ & \multicolumn{1}{|c|}{$\begin{array}{l}\text { Strength } \\
{[\mathrm{MV} / \mathrm{m}]}\end{array}$} \\
\hline R008 & 0.26 & 20 & 12.31 & 21.4 \\
\hline R009 & 0.26 & 20 & 12.31 & 23.5 \\
\hline R010 & 0.26 & 20 & 12.31 & $>22.3^{1}$ \\
\hline R168 & 0.51 & 40 & 10.15 & $23.8^{2}$ \\
\hline R169 & 0.51 & 40 & 10.15 & $17.6^{2,3}$ \\
\hline R170 & 0.51 & 40 & 10.15 & $22.3^{2}$ \\
\hline R173 & 0.51 & 40 & 10.15 & $21.4^{2}$ \\
\hline R213 & 1.3 & 100 & 10.67 & $>26.5^{1}$ \\
\hline R214 & 1.3 & 100 & 10.67 & 20.3 \\
\hline R215 & 1.3 & 100 & 10.67 & 26.1 \\
\hline
\end{tabular}

${ }^{1}$ Exceeded voltage capability of test stand

${ }^{2}$ Conditioning test shown in Fig. 5

${ }^{3}$ Damaged in manufacturing 
Table III: HGI Samples with thick metal layers.

\begin{tabular}{|l|c|c|c|l|}
\hline HGI & $\begin{array}{c}\text { Rexolite } \\
{[\mathrm{mm}]}\end{array}$ & $\begin{array}{c}\text { Insulator/ Metal } \\
\text { Ratio }\end{array}$ & $\begin{array}{l}\text { Length } \\
{[\mathrm{mm}]}\end{array}$ & $\begin{array}{l}\text { Strength } \\
{[\mathrm{MV} / \mathrm{m}]}\end{array}$ \\
\hline R011 $^{1}$ & 0.26 & 0.833 & 12.36 & 10.5 \\
\hline R012 $^{1}$ & 0.26 & 0.833 & 12.36 & 11.2 \\
\hline R013 $^{2}$ & 0.26 & 0.833 & 11.51 & 14.1 \\
\hline R014 $^{2}$ & 0.26 & 0.833 & 11.43 & 10.9 \\
\hline
\end{tabular}

${ }^{1}$ Dielectric end layers

${ }^{2}$ Metal end layers 


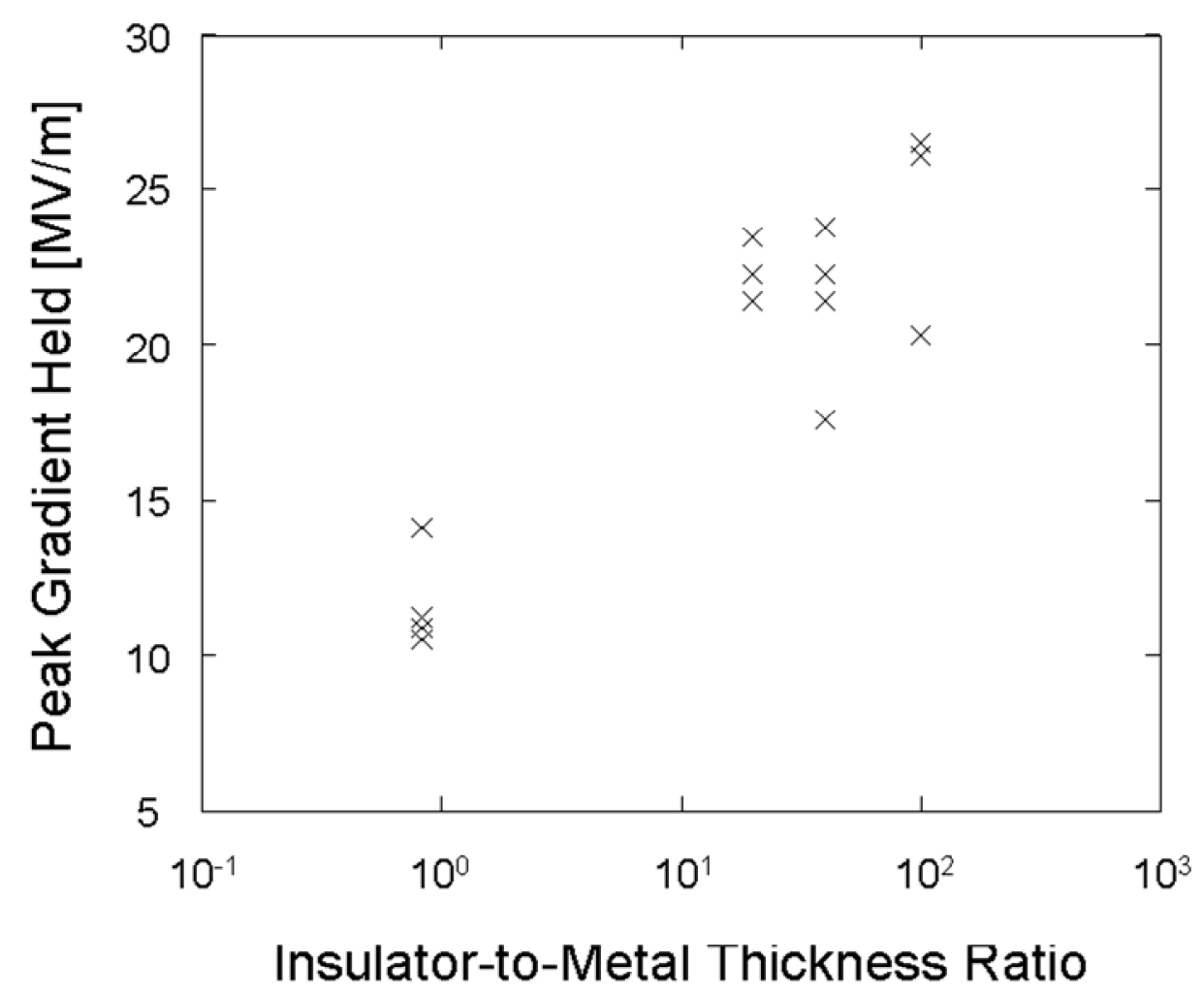

Figure 9. Observed performance of $\sim 11 \mathrm{~mm}$ tall HGIs as a function of $I / M$, from Tables 2 and 3. Outlier at $I / M=40$ is R169, which was damaged prior to testing. Cause of outlier at $I / M=100$ is unknown. 


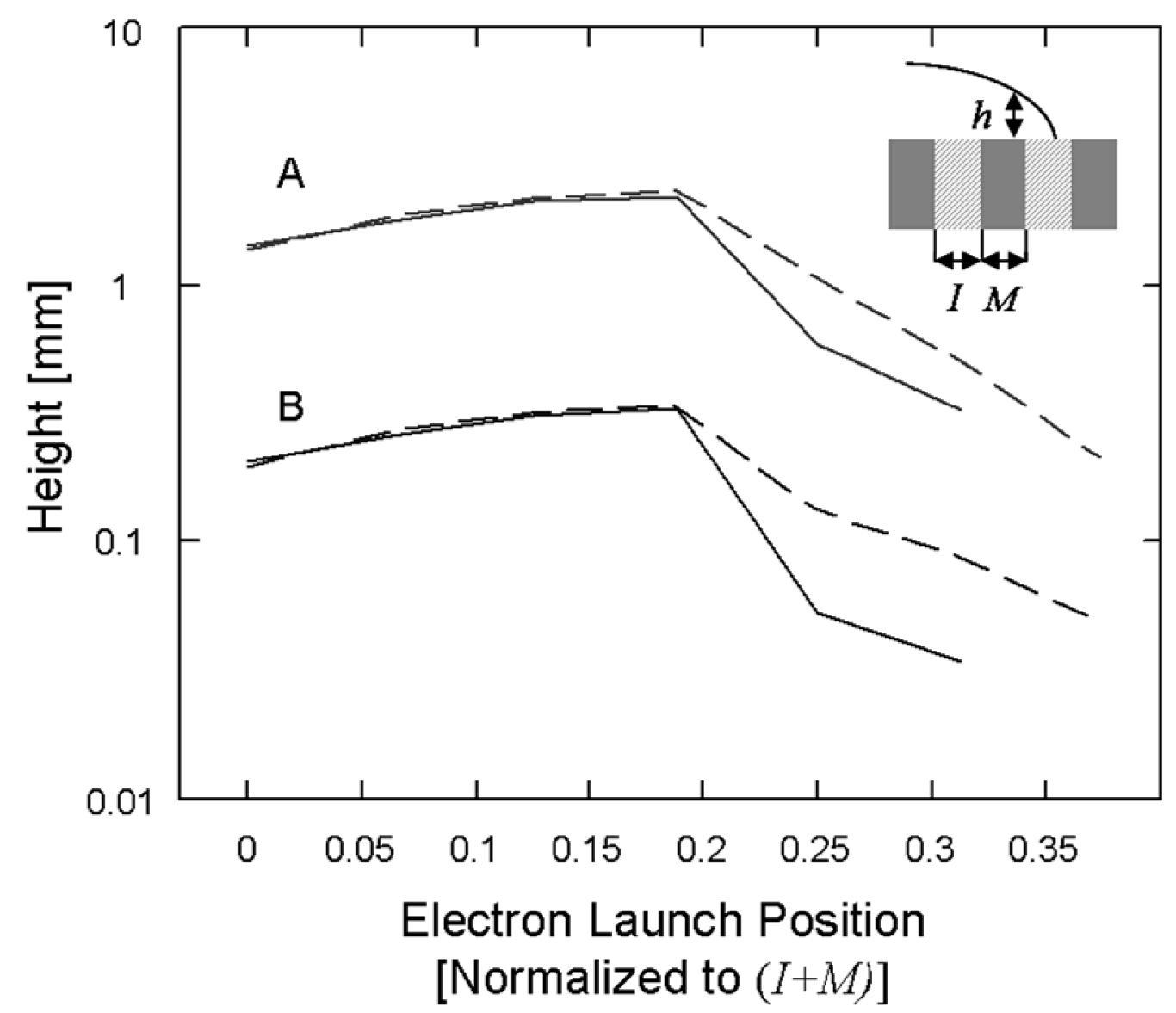

Figure 10. Simulated electron heights $h$ above HGI surface after traveling a distance $\frac{I+M}{2}$ downrange. Electrons were released normal to the HGI surface with an initial kinetic energy of $2 \mathrm{eV}$, into average applied fields of $1 \mathrm{MV} / \mathrm{m}$ (dash) and $100 \mathrm{MV} / \mathrm{m}$ (solid). HGIs simulated had equal metal and dielectric layer thicknesses, and structure periods $(I+M)$ of $4 \mathrm{~mm}(\mathrm{~A})$ and $0.57 \mathrm{~mm}$ (B). Horizontal axis corresponds to the initial position of the electrons on the HGI surface, normalized by the HGI structure period. Only electrons normally able to escape the HGI surface were considered here. 


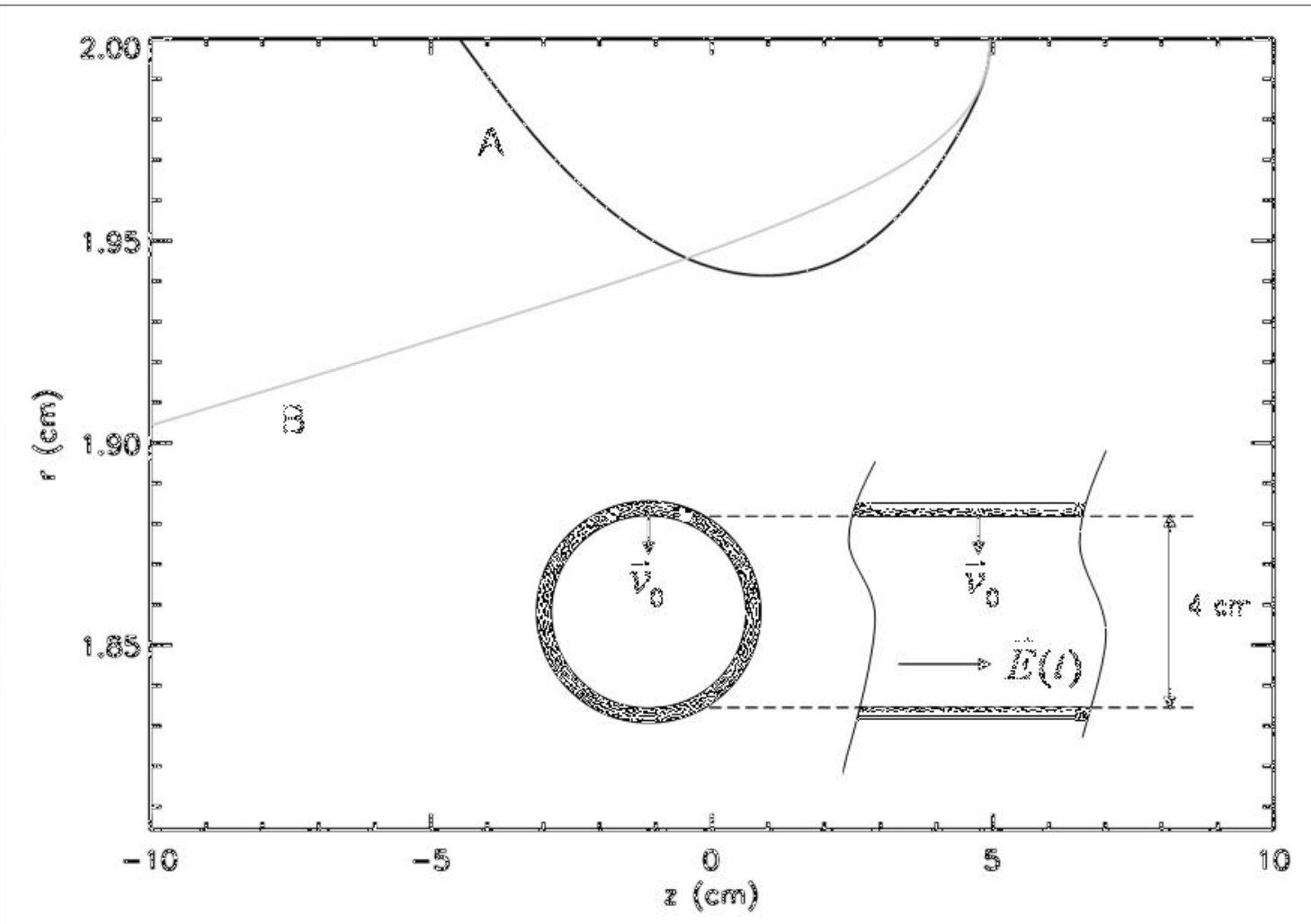

Figure 11. Trajectory of an electron launched normal to the interior surface of a $4 \mathrm{~cm}$ diameter dielectric tube with initial energy $2 \mathrm{eV}$. Curve A shows the trajectory including the magnetic field generated by displacement current in the simulation volume, while curve B shows the trajectory neglecting magnetic effects. During the leading edge of the applied voltage waveform the magnetic field deflects the electron away from the wall, while on the trailing edge the electron is deflected towards the wall. Inset shows front and side views of the simulation geometry. 


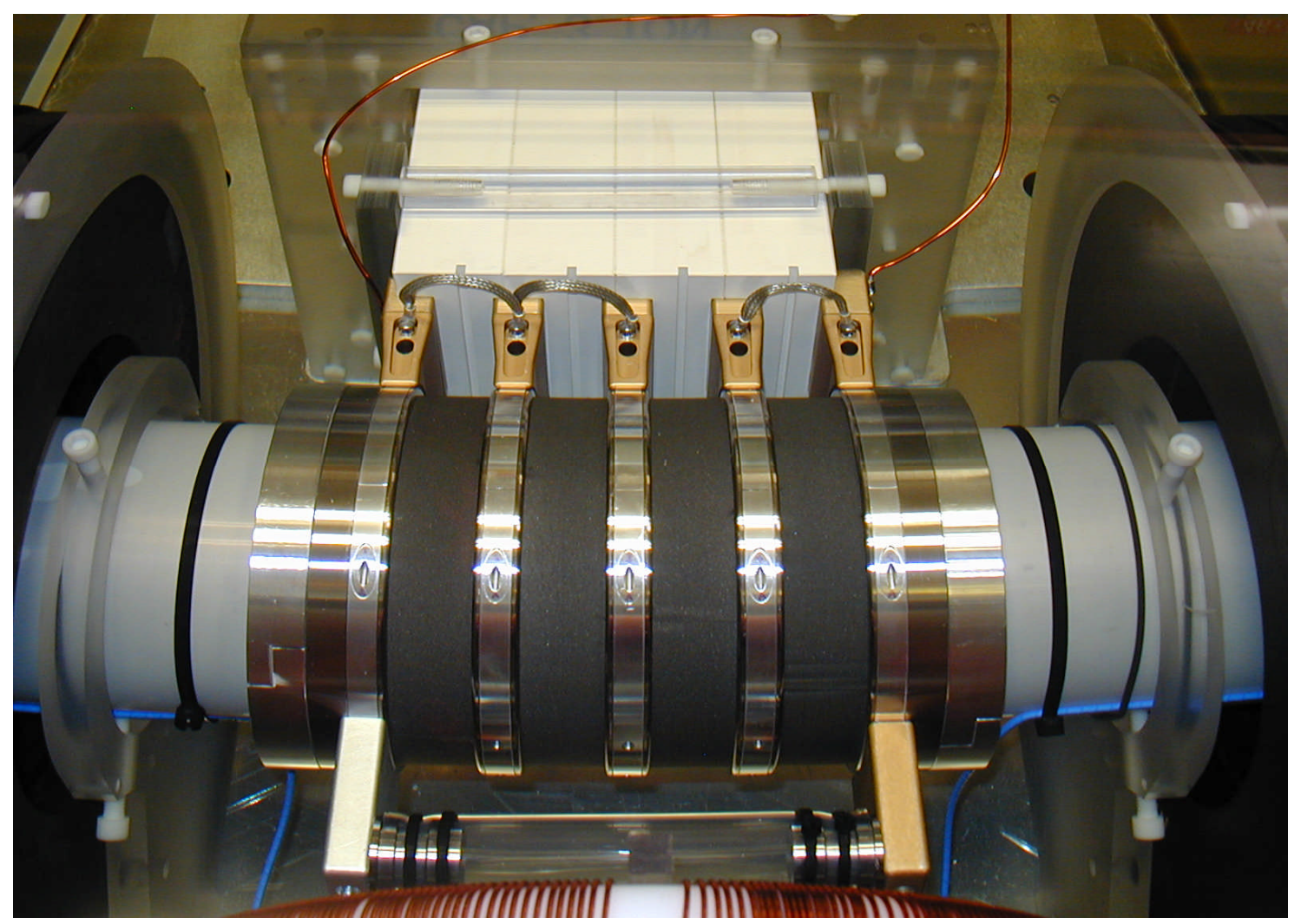

Figure 12. (Color online.) Vacuum insulator assembly for the dielectric wall accelerator described in Ref. 26, consisting of four HGI beam tubes. Cast pulse-forming line assemblies are visible at top of figure. 